\title{
ANALYSIS OF POPULATION GROWTH THROUGH DELAY DIFFERENTIAL EQUATIONS
}

\author{
CARLOS JULIO MAYORGA ARIAS ${ }^{1}$, (Professor, Universidad Central del Ecuador), \\ ANTONIO SIRVENT ${ }^{2}$, (Universidad de Alicante) \\ ALEJANDRO LEÓN CAICEDO ${ }^{3}$, (LEONCA)
}

${ }^{1}$ Quito, Ecuador (e-mail: cjmayorga@ hotmail.com)

${ }^{2}$ Alicante, Spain (e-mail: antonio.sirvent@ua.es)

${ }^{3}$ Quito, Ecuador (e-mail: alejandroleoncaicedo@hotmail.com)

Corresponding Author: Mayorga Carlos (e-mail: cjmayorga@hotmail.com).

\begin{abstract}
In this work, an analysis of the birth rate and mortality in Venezuela was carried out taking this data, to more than the number of inhabitants, of the year 2019, which is a period that was considered by alterations that were presented in recent months by the presence of COVID-19. This analysis was carried out through the differential equations with delay, applying for resolution the non-standard numerical methods. The proposed model allows to obtain the projection for the following periods, in this case it was applied to obtain the number of inhabitants of the year 2020; MATLAB software was used to run the proposed model and result in the population of Venezuela for later years from 2019. The result obtained by developing the model proposed on the basis of differential equations with delay, allows to analyze the situation of a country or geographical area, in this case Venezuela, according to various factors such as the age of maturity of the population, which was one of the variables that had a considerable impact to obtain the projection of inhabitants.
\end{abstract}

INDEX TERMS Differential equations with delay, mortality rate, Malthus model, midpoint. 


\title{
ANALYSIS OF POPULATION GROWTH THROUGH DELAY DIFFERENTIAL EQUATIONS
}

\author{
CARLOS JULIO MAYORGA ARIAS ${ }^{1}$, (Professor, Universidad Central del Ecuador), \\ ANTONIO SIRVENT ${ }^{2}$, (Universidad de Alicante) \\ ALEJANDRO LEÓN CAICEDO ${ }^{3}$, (LEONCA) \\ ${ }^{1}$ Quito, Ecuador (e-mail: cjmayorga@ $@$ hotmail.com) \\ ${ }^{2}$ Alicante, Spain (e-mail: antonio.sirvent@ua.es) \\ ${ }^{3}$ Quito, Ecuador (e-mail: alejandroleoncaicedo@ hotmail.com) \\ Corresponding Author: Mayorga Carlos (e-mail: cjmayorga@hotmail.com).
}

\begin{abstract}
In this work, an analysis of the birth rate and mortality in Venezuela was carried out taking this data, to more than the number of inhabitants, of the year 2019, which is a period that was considered by alterations that were presented in recent months by the presence of COVID-19. This analysis was carried out through the differential equations with delay, applying for resolution the non-standard numerical methods. The proposed model allows to obtain the projection for the following periods, in this case it was applied to obtain the number of inhabitants of the year 2020; MATLAB software was used to run the proposed model and result in the population of Venezuela for later years from 2019. The result obtained by developing the model proposed on the basis of differential equations with delay, allows to analyze the situation of a country or geographical area, in this case Venezuela, according to various factors such as the age of maturity of the population, which was one of the variables that had a considerable impact to obtain the projection of inhabitants.
\end{abstract}

INDEX TERMS Differential equations with delay, mortality rate, Malthus model, midpoint.

\section{INTRODUCTION}

The application of mathematics not only involves branches such as physics or engineering but can also be used in other areas such as economics, where the data or economic information obtained from a population can be represented in an economic model, in which various methods can be applied as is the case of Differential Equations. Much of the analysis that is carried out in economics is not purely qualitative, but also concerns the use of mathematical methods to better demonstrate the economic variables and their variations in a given period of time. [1]

Therefore, this paper proposes a population growth model in which differential equations with delay allow to determine a projection of the population from the birth rate, the mortality rate, the number of inhabitants and the maturity of a population, in this case of Venezuela.

\section{DIFFERENTIAL EQUATIONS}

They are those in which one or more derivatives affect the unknown function of an equation. There are two types of differential equations (DE): ordinary ones, which are in which a single variable or derivative affects the unknown function; and partial differential equations, which has two or more derivatives that affect the unknown function. [12]

DE that havens a degree of resolution of greater difficulty are usually applied in branches such as medicine, biology, engineering, physics and also in economics. When more complex cases of DE are presented, solving them requires the application of two perspectives: the first, covers qualitative analysis, which is related to the application of dynamical systems; while the second perspective, numerical methods are applied from which values are obtained that differ in the level of certainty. [15]

According to Rivadeneira and Suriaga, the degree ED, have the symbology presented in Equation (1]: [16]n

$$
F\left(x, y,{ }^{\prime \prime}, \ldots, y^{(n)}\right)=0
$$

In the above function, $\mathrm{F}$ symbolizes that a function has variables, but if other variables are added to it, the result is Equation (2) shown below:n+2

$$
y^{(n)}=f\left(x, y, y^{\prime \prime}, \ldots, y^{(n-1)}\right)
$$




\section{DELAY DIFFERENTIAL EQUATIONS}

The application of DDE has become a method widely applied within the Economy, because they allow to express in a mathematical way the information of a certain economic phenomenon.

In DDE there is a significant relationship between time and delay; when you want to determine the solution for an approach, you start from an initial function that is determined in a period or range of time. [3]

This type of equations is composed of the following variables: variation of the state that is symbolized with, $x$ time, taking into account each range or period that is represented with $\mathrm{t}$, in addition in differential equations with delay it is necessary to have data from preliminary or previous moments. [14]

\section{NON-STANDARD NUMERIC METHODS}

The numerical methods use algorithms that allow to find approximate mathematical solutions for the mathematical approaches that have greater complexity. [2]

Using numerical methods allows the dynamic properties of differential equations to be preserved. To obtain a precise solution to mathematical approaches, everything depends on the method applied; thus, the solutions obtained can be periodic, spurious or also chaotic. [17]

\section{POPULATION GROWTH MODELS}

The study of population growth focuses its origin on very old writings from China in which various factors that affect population growth are described such as: insufficient food production, confrontations or wars, and even marriages performed at very young ages that can increase the infant mortality rate. [8]

In order for the population to grow or be reduced, it depends mainly on three processes, which are: natural growth, which is that obtained from the difference between the number of births and deaths that exists in a territory in a given period of time; social growth, which depends on population movements, that is, the number of people leaving for other geographical areas and the inhabitants migrating within a locality; and total growth, which is that in which the two previous types of growth are immersed. [4]

\section{METHODOLOGY}

In the previous section some notions about ED and DDE were exposed, in the following sections the concepts and models of differential equations proposed for the economic field and on the basis of which the analysis of the mortality rate in Venezuela is carried out; to be exact, Malthus' model will be exposed. Due to the COVID-19 pandemic, the country's death rate has varied considerably from month to month. Therefore, through the DDE an analysis of the mortality rate of the year 2019 is developed, and as a result the population will have been projected for different years after the year that is taken as initial, that is, 2019, this in order to expose a model for the calculation of the projection of the population.
It is planned to use MATLAB software that is a platform for programming and numerical computation used by millions of engineers and scientists to analyze data, develop algorithms and create models". [18]

\section{DEVELOPMENT}

The best-known model of population growth is that of Malthus, who states that the birth rate and mortality rate will always remain constant and that therefore the population will remain growing, which can be applied in short periods of time. If, on the other hand, the availability of resources that enable the population to increase is reduced or scarce, the growth rate is shortened. [7]

Malthus in 1798, proposed a mathematical model of birth and mortality, depending on the number of individuals that make up the population at the instant studied, denoted by $\mathrm{x}(\mathrm{t})$, where the values of $\mathrm{t}$ can only be positive. [10]

In the mathematical model $x^{\prime}(t)$ the variation of the population size is represented and Equation (3) is generated, which is presented below:

$$
x^{\prime}(t)=a x(t)-b x(t)
$$

The value observed in Equation (3) represents the birth rate, while b symbolizes mortality and through these two elements the intrinsic rate of growth is determined, as shown in Equation (4):

$$
p=a-b
$$

However, this model differs with the information or data that are part of the analysis in the case proposed in this paper, since it is necessary to study the evolution of the mortality rate of the Venezuelan population in 2019 and the influence of the COVID-19 pandemic.

\section{A. PROPOSED MODEL}

To begin with the approach of the equation of this work, we use as a base a model of Malthus for the calculation of the population, which can be considered as the most elementary model, in which a rate of births and mortality greater than 0 is assumed, then equation (5) is presented.

$$
N^{\prime}(t)=-d N(t)+b N(t)
$$

The behavior of this system would be limited by births and deaths, which shall be represented by the letters $d$ and respectively.

Therefore, the equation from which you will start to develop the proposed model, focuses on including the data mentioned above, Equation (6):

$$
x^{\prime}(t)=-d x(t)+b x(t)
$$

As seen in the above equation, $y^{\prime}(t)$ represents the analysis of the population, where $\mathrm{n}$ is the birth rate and $\mathrm{m}$ symbolize the mortality rate; however, in this model is considered an additional variable, which affects the reproduction of the population as is maturity. This factor has changed today and 
adapts to several factors; the maturity which is related to reproduction entails a period which it is necessary to adapt the proposed model to one which includes the delay, by means of the maturity analysis; this factor shall be represented by the letter, $\mathrm{T}$ as shown in Equation (7):

$$
y^{\prime}(t)=-m y(t)+n y(t-T)
$$

Once you have the equation with the necessary factors included, we proceed to investigate the birth rate of the year 2019 of Venezuela, which according to the Pan American Health Organization is [6] 19,7 per 1000 inhabitants, while the mortality rate that was obtained in this same year is 7,1 .

In addition, as mentioned in previous paragraphs, maturity is also considered as another important factor for the proposed equation. It is estimated that, for this variable, the period is 18 years, because this is an adequate age both biologically and legally. In such a way that, all this data is replaced in Equation (7), thus obtaining the Equation (8) shown below:

$$
y^{\prime}(t)=-7.1 y(t)+19.7 y(t-18)
$$

As a next step, the total population of Venezuela for the same period, that is, the year 2019, was investigated. According to the World Bank, a total population of [11]28,515,929 inhabitants was obtained during this period. Now that you have this variable, $y(0)=28.515 .929$ as the initial population in the year 2019, to analyze the data of the proposed model. The system has been analyzed using the midpoint method because it facilitates estimating a point in the modeled system by analyzing the slope and distance between two points within a period, as shown in Equation 97:

$$
\left(x_{i}+0.5 * h i, y_{i}+0.5 * k 1 h\right)
$$

To develop the model with the data already contained in equation (8), it will be necessary to define the limits, such as the step size for the simulation. It will be applied in 18 intervals because it is the value of the delay within to delay differential equation, this because in Latin American countries it is considered as adulthood and as a period of maturity when a person reaches 18 years, so we have Equation (10):

$$
\text { Limits [Initial, Final }]=[0,18]
$$

In addition, it has been defined that the size of the step will be evaluated in 1, because this information is analyzed annually, thus obtaining the expression shown in equation (11):

$$
h=1
$$

\section{B. APPLICATION IN MATLAB PROGRAM}

The MATLAB software will be the tool through which the simulation of the system will be developed, since this program offers the possibility of analyzing the solution pair to an DDE.

The code by which the simulation of the system will be developed is as follows:

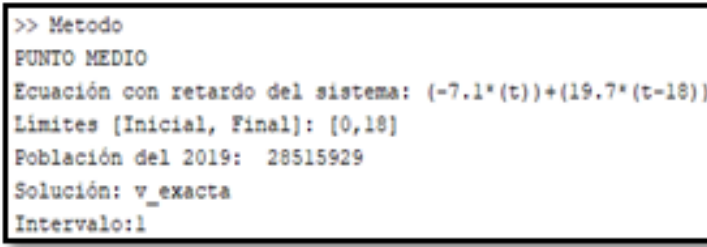

FIGURE 1. System Data.

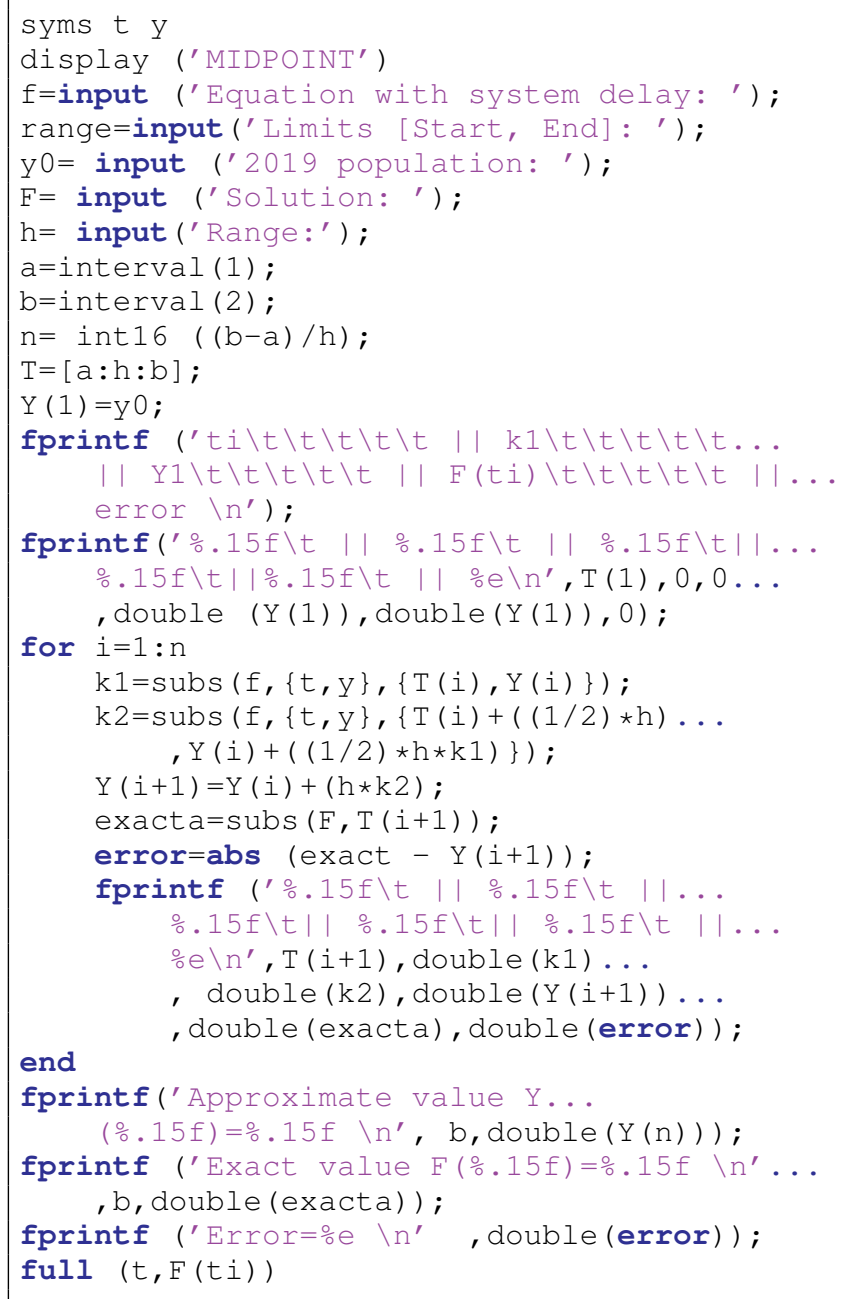

Within the encoding it is necessary to initially set two variables: y representing the population size and time as an independent variable. $t$ Then as a next point, we proceed to analyze that the solution of the same is an indispensable factor in the development, so it will be necessary to simulate the solution by means of the following coding:

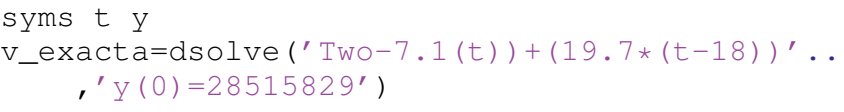

The solution will be called $v_{\text {exacta }}$; after this step it is essential that you start the process of simulation of the program. 


\section{RESULTS}

Once the respective coding is obtained, which was presented in the previous section, the table is obtained with the data that is displayed in Figure 1:

Once the simulation was entered, the model of the system in table shape was designed as can be seen in Figure 2:

By means of simulation, the population was estimated for 18 years later; among the data that can be highlighted the approximate population for the year 2020 would be 28515580,699999999254942 in habitants, which in whole numbers the result is 28515581 people. The population as of 2020 has reached 28,475 . 668 compared to the proposed system, marks a margin of error of $0.78 \%$, which has allowed to calculate the projection of the population in very close periods.

\section{CONCLUSIONS}

The models of population calculation through DDE applying the method of the midpoint, allows to estimate a result close to the population base with a margin of error extremely low.

It is important to mention that the modeled system does not present a level of total certainty, but this occurs when you have the condition that as the number of periods increases its reliability decreases.

The application of the proposed model is an alternative solution, which does not have a representative cost and whose results are convincing if applied in atypical situations such as an environmental crisis or in contexts of health emergency, such as the one currently experienced with the pandemic due to the COVID-19 virus.

This model, in addition, can be the starting point for other types of economic analysis related to population growth, such as determining the variation in population growth from one year to the next, establishing the growth or decrease of a specific population group and having a primary influence on the economy such as the PEA among others.

Obtaining the results regarding population growth not only means obtaining the number of inhabitants of a country in a period of time, but also based on these results public or economic policies are proposed that affect this variable.

On the other hand, the proposed model can serve as a basis for other studies to consider additional variables that can be included in the proposed equation, such as migration, which would also have great significance if it were Venezuela, due to the large number of inhabitants who have left the country due to the economic and political crisis that is currently being experienced. As observed in the model development and in the results, maturity was a variable with a substantial incidence, since the age of 18 years is considered as data to include within the equation, and that based on this factor the population was projected for the year 2020. The margin of error will be greater if a variable comprising a greater number of periods is applied to the model.

\section{REFERENCES}

[1] Anido de López, M., And Simoniello de Alvarez, A. M. Las ecuaciones diferenciales como herramientas disparadoras de un trabajo de formación docente.

[2] Araujo, E. Métodos numéricos para simulación en la ingeniería. https://www.esss.co/es/blog/ metodos-numericos-para-simulacion-en-la-ingenieria/ Ultimo acceso: 2021-11-22.

[3] BEL, A. L. Soluciones oscilatorias en ecuaciones diferenciales con retardo.

[4] Chaves, E. Centro centroamericano de población - universidad de costa rica. https://ccp.ucr.ac.cr/cursos/demografia_03/materia/5_crecimiento. htm Último acceso: 2021-04-20.

[5] DE Buenos Aires, U. Universidad de buenos aires. http://cms.dm.uba.ar/academico/materias/1ercuat2016/ecuaciones diferenciales_con_retardo/clase1.pdf Ultimo acceso: 2021-04-19.

[6] DE LA SAlud, O. P. Organización panamericana de la salud. https://www.paho.org/salud-en-las-americas-2017/?page t_es=informes\%20de\%20pais/venezuela\&lang=es\#: :text=El\% 20crecimiento\%20demogr\%C3\%A1fico\%20anual\%20fue, m\%C3\% A1s\%20de\%2085\%25\%20del\%20total Ultimo acceso: 2021-04-18.

[7] E. PARra, W. G. Y. W. P. Modelos de crecimiento poblacional: Enseñanza-aprendizaje desde las ecuaciones recursivas. Formación Universitaria 12, 1 (2019), 25-34.

[8] F. Manrique, A. M. Y. J. O. Crecimiento poblacional y políticas públicas. Apuntes del CENES 27, 44 (2007), 149-162.

[9] GómEz, D. Creative commons. https://gomez-metodos-numericos. webnode.es/ecuaciones-diferenciales-ordinarias/punto-medio/ Ultimo acceso: 2021-04-19.

[10] LIZ, E. Sobre ecuaciones diferenciales con retraso, dinámica de poblaciones y números primos. Materials Matemátics, 17 (2006), 1-24

[11] Mundial, B. Población, total - venezuela, rb. https://datos. bancomundial.org/indicator/SP.POP.TOTL?locations=VE Último acceso: 2021-04-18.

[12] NaÓn, C. M., Rossignoli, R., And Santángelo, E. M. Ecuaciones diferenciales en física. Series: Colección Libros de Cátedra (2014).

[13] REgalado, A. Universidad de el salvador. http://ri.ues.edu.sv/id/eprint/ 9421/1/19201018.pdf Último acceso: 2021-03-8.

[14] Regalado Bonilla, A. N. Ecuaciones diferenciales con retardo discreto y aplicaciones.

[15] Reyes Ortiz, G. E. Modelos dinámicos y ecuaciones diferenciales en gestión de empresas. Tech. rep., Editorial Universidad del Rosario, 2012.

[16] Sánchez, M. A. S., Pacheco, J. L. R., And Solís, H. P. D. Las ecuaciones diferenciales y su aplicación en la economía. E-IDEA Journal of Business Sciences 2, 4 (2020), 1-7.

[17] Solis, F. Métodos numéricos no estándar. CIMAT (2006), 1-9.

[18] The MathWorks, I. Matlab. https://www.mathworks.com/products/ matlab.html Último acceso: 2021-04-15. 


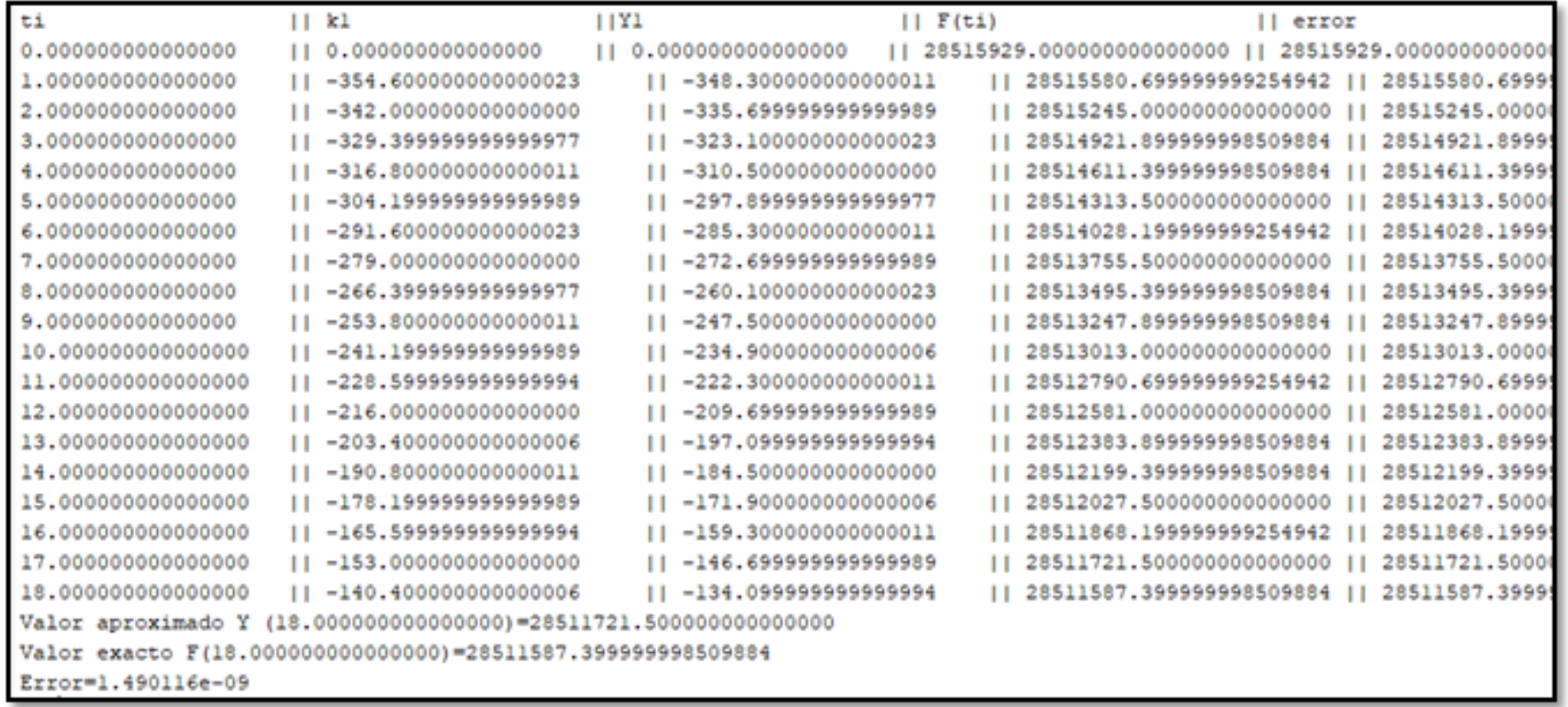

FIGURE 2. System Simulation. 